\title{
Optimized Subsurface Irrigation System (OPSIS): Beyond Traditional Subsurface Irrigation
}

\author{
M. H. J. P. Gunarathna 1,2,* (D), Kazuhito Sakai ${ }^{3, *}$, Tamotsu Nakandakari ${ }^{3}$, Momii Kazuro ${ }^{4}$, \\ Tsuneo Onodera ${ }^{5}$, Hiroyuki Kaneshiro ${ }^{6}$, Hiroshi Uehara ${ }^{6}$ and Kousuke Wakasugi ${ }^{7}$ \\ 1 United Graduate School of Agricultural Sciences, Kagoshima University, 1-21-24 Korimoto, Kagoshima-shi, \\ Kagoshima 890-0065, Japan \\ 2 Faculty of Agriculture, Rajarata University of Sri Lanka, Puliyankulama, Anuradhapura 50000, Sri Lanka \\ 3 Faculty of Agriculture, University of the Ryukyus, 1 Senbaru, Nishihara-cho, Okinawa 903-0213, Japan; \\ zhunai@agr.u-ryukyu.ac.jp \\ 4 Faculty of Agriculture, Kagoshima University, 1-21-24 Korimoto, Kagoshima-shi, Kagoshima 890-8580, \\ Japan; momii@agri.kagoshima-u.ac.jp \\ 5 Paddy Research Co., Ltd., 9 Haraoka, Minamikawa-machi, Tome-shi, Miyagi 987-0432, Japan; \\ paddy@cocoa.ocn.ne.jp \\ 6 Midori Net Okinawa, 453-3 Motobu, Haebaru-cho, Okinawa 901-1112, Japan; \\ kanesiro.dokairen@gmail.com (H.K.); uehara@dokairen-okinawa.jp (H.U.) \\ 7 Institute for Rural Engineering, National Agriculture and Food Research Organization, 3-1-1 Kannondai, \\ Tsukuba-shi, Ibaraki 305-8517, Japan; kousuke@affrc.go.jp \\ * Correspondence: janaka78@gmail.com (M.H.J.P.G.); ksakai@agr.u-ryukyu.ac.jp (K.S.); \\ Tel.: +81-70-4419-3534 (M.H.J.P.G.); +81-89-895-8783 (K.S.); Fax: +81-89-895-8734 (K.S.)
}

Received: 25 May 2017; Accepted: 17 July 2017; Published: 12 August 2017

\begin{abstract}
Technologies that ensure the availability of water for crops need to be developed in order for agriculture to be sustainable in the face of climate change. Irrigation is costly, so technologies need to be improved or newly developed, not only with the aim of the sustainable use of precious water resources, but also with the aim of reducing associated labor and energy costs, which lead to higher production costs. OPSIS (optimized subsurface irrigation system) is a super water-saving subsurface irrigation system developed to irrigate upland crops by soil capillarity. It is an environmentally-friendly, solar-powered automatic irrigation method with minimum energy consumption and operational costs. In soils vulnerable to drought damage, OPSIS can outperform other irrigation methods. This technical note introduces OPSIS.
\end{abstract}

Keywords: automatic; environment friendly; upland crops; climate change; water saving

\section{Introduction}

Rainfed agriculture occupies $80 \%$ of the world's agricultural lands and currently contributes $60 \%$ of the world's food production [1]. However, the sustainability of rainfed agriculture in some regions is in peril as it is gravely threatened by climate change [2], as a result of which not only food security [3] but also the social structure [4] in many countries is in danger. Since water availability directly influences the efficient use of all other inputs, better water availability in turn ensures optimum yields from a given combination of inputs [5]. Therefore, emerging irrigation technologies ideally should be developed to enhance crop water availability in order to make agricultural practices sustainable in the long run. Although shifting from rainfed to irrigated agriculture or from low-efficiency to high-efficiency irrigation methods offers important remedial measures against a changing climate, adaptation could be inhibited by the reluctance of farmers to adopt practices that elevate operational costs, such as high-efficiency irrigation methods. Therefore, new irrigation technologies would be 
more likely to be adopted if they were designed to save precious water resources and at the same time keep associated labor and energy costs as low as possible.

Various irrigation methods, such as surface, subsurface, sprinkler, and drip irrigation, can be used to irrigate upland crops. The method selected would depend on physical, economic, and social factors, and in turn determines the efficiency of resource use, economic viability, and sustainability of upland farming systems [6]. In the past, surface irrigation methods such as basins, borders, and furrows have been used to irrigate upland crops in many regions of the world, owing to their simplicity and low cost. In surface irrigation methods, water flows over the entire field or along furrows by gravity. When flowing, water infiltrates the soil and provides irrigation water to the root zone of crops. The uniformity of distribution and application efficiency basically depends on the degree of land leveling; therefore, it consumes high labor costs for land preparation [7,8]. With increasing energy and labor costs, however, and with increasing demand for diminishing water resources, surface irrigation has been replaced to some extent by subsurface, sprinkler, or drip irrigation methods. However, surface irrigation still is the major irrigation method used to irrigate upland crops worldwide. Drip and sprinkler irrigation methods were developed for high-frequency irrigation of crops by means of a systematically installed pipe network and emitting devices [6,9]. In drip and sprinkler systems, water is supplied under pressure and water often passes through various types of filters depending on the type of irrigation system and water source [9]. Sprinkler irrigation-including solid sets, periodic move or continuous move systems, traveling guns, and boom sprinkler systems-has advantages over surface irrigation in terms of its high efficiency of water application, ease of fertilizer application, and high resultant crop yields [10]. However, it also has some drawbacks such as high setup costs, high operational costs due to its high energy and maintenance requirements, and its tendency to be adversely affected by wind conditions [7]. Drip irrigation (irrigation systems that are designed to slowly apply water to individual points), on the other hand, overcomes some of these drawbacks by way of low energy requirements and not being affected by wind. It has distinctive water and energy saving features while supporting the agronomy of crops in addressing the challenges faced in irrigated agriculture [11]. However, it may perform poorly with crops that have high water requirements. The major drawback of drip irrigation systems is the clogging of emitters, which leads to poor performance and calls for frequent maintenance. Further, damage by weathering and farm machinery partly explains why such an appealing technology remains unpopular among farmers $[6,7,10]$. Although subsurface drip irrigation (application of water below the soil surface by drip emitters) systems have been developed to overcome the prevailing practical issues of drip irrigation, they have not performed as expected, since they further aggravate the problem of poor water distribution efficiency due to emitter clogging [12-14].

Therefore, new irrigation methods are being developed to irrigate upland crops that aim to use water more efficiently and effectively while minimizing costs so as to improve profitability and sustainability. In this regard, it is essential to minimize major water losses through evaporation, surface runoff, and percolation in order to economize on the limited availability of water, while also driving down the labor and energy requirements and keeping operational costs to a minimum. Therefore, any new design should be able to ensure (i) high application efficiency with uniform distribution; (ii) low capital investment; (iii) low energy and labor requirements to minimize operational costs; (iv) automated operation with minimum supervision; (v) minimum influence from weather, topography, or soil type; (vi) minimum disturbance to other management practices; and (vii) environmentally-friendly technology.

\section{Optimized Subsurface Irrigation System (OPSIS)}

Capillarity, upward water movement in tubes due to cohesion, adhesion and surface tension forces, can also be happen in soil. In soils, water can move upwards through soil pore spaces between soil particles. The height of capillary rise is dependent on pore size as smaller soil pores show higher capillary rise. Our newly developed "optimized subsurface irrigation system" (OPSIS) is designed to irrigate upland crops by means of the capillarity of soil. Water is released by perforated pipes just 
below the root zone and water moves upward due to the capillarity of soil in order to irrigate the crops. Subsurface irrigation methods perform better in soils that are vulnerable to drought damage (soils with low available water), and hence OPSIS shows better results than other irrigation methods in such environmental contexts. OPSIS shows super water-saving capability as it can minimize runoff, evaporation and percolation. Since only a small solar-powered pump is used to make the elevation head, OPSIS does not incur any ongoing energy costs, and since it can operate with minimal labor as an automated system, it should drastically bring down the operational costs of irrigation.

\section{Technical Details of OPSIS}

In OPSIS, water is elevated using a solar powered submersible pump to create an elevation head to a higher level, it then flows along the gravity. Subsurface perforated pipes leak water while flowing by gravity, then soil capillarity provides the irrigation water to the crops. OPSIS consists of a main water control unit and a water distribution system (Figure 1). After series of laboratory and field experiments on the irrigation amount, water distribution and cost effectiveness under local soil conditions in Okinawa, the dimensions and materials of construction for each part were determined.

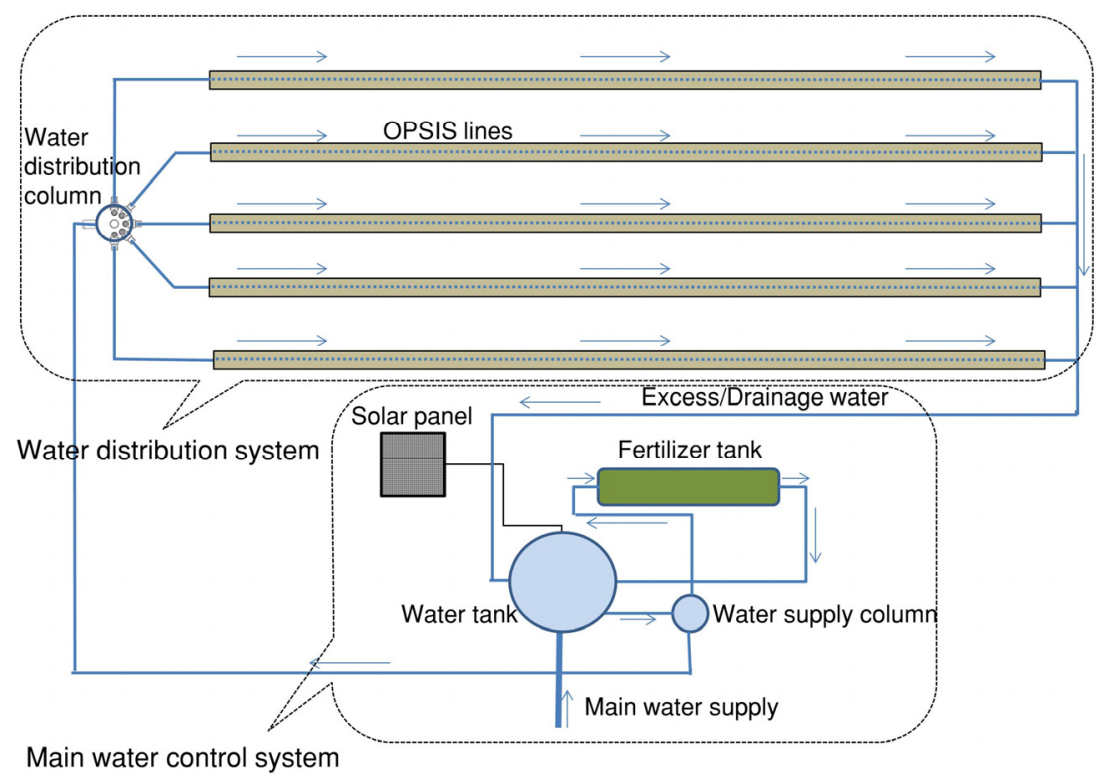

Figure 1. Schematic diagram of Optimized subsurface irrigation system (OPSIS).

\subsection{Main Water Control System}

The main water control system includes a water tank to store water temporarily, a solar pump to elevate the water, a water supply column to control the water flow, and a fertilizer tank to facilitate fertigation. It regulates both the quantity and the pressure of all water coming into the irrigation system and provides controlled water and fertilizer flow out to the water distribution system.

\subsubsection{Water Tank}

The size of the water tank (Figure 2) varies according to the source of water and the requirements of the farmer. The supply of water, such as from an irrigation canal or groundwater, is regulated by a ball tap. Because of the head difference between the water tank and the field, excess water from the OPSIS lines and drainage water from the field flows back to the water tank. A solar-powered submersible pump is used to pump the water out from the tank and into the water supply column. 


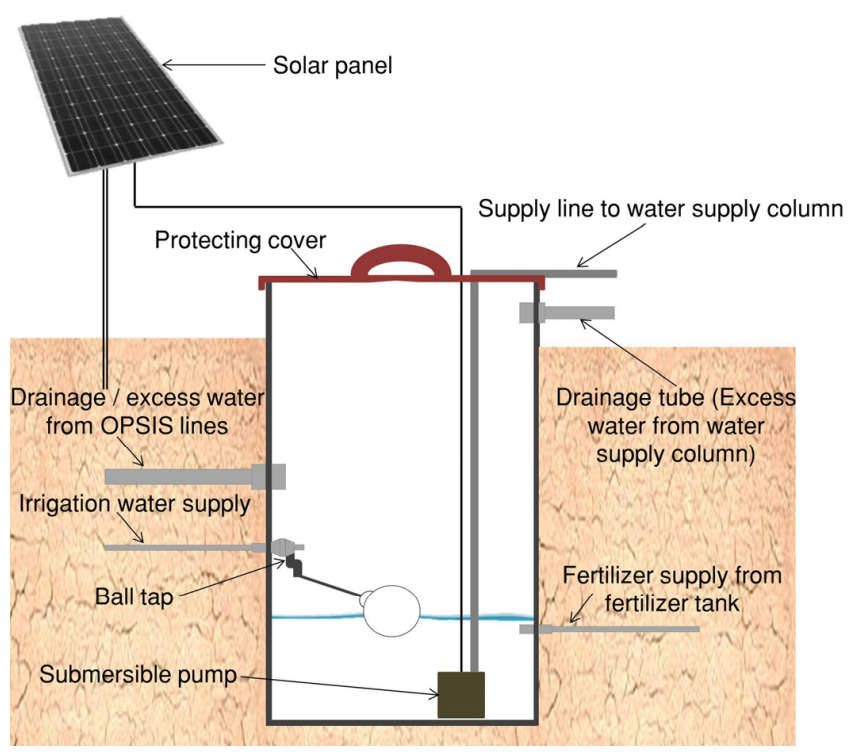

Figure 2. Schematic diagram of water tank.

\subsubsection{Water Supply Column}

The water supply column (Figure 3) provides a controlled and constant flow of water and fertilizer into the water distribution system. A constant water level is maintained in the column by means of a drainage tube attached to it. The pressure and volume of water discharged to the water distribution system is controlled by a micro tubing mechanism in the column. A thin tube wrapped around the center pipe sends the water smoothly and slowly into the outlet of the water column. The volume of discharge depends on the water height in the column, and can therefore be controlled by adjusting the height of the drainage tube. The water column also connects to the fertilizer tank and provides a controlled flow of water to the water distribution column through an underground pipe.

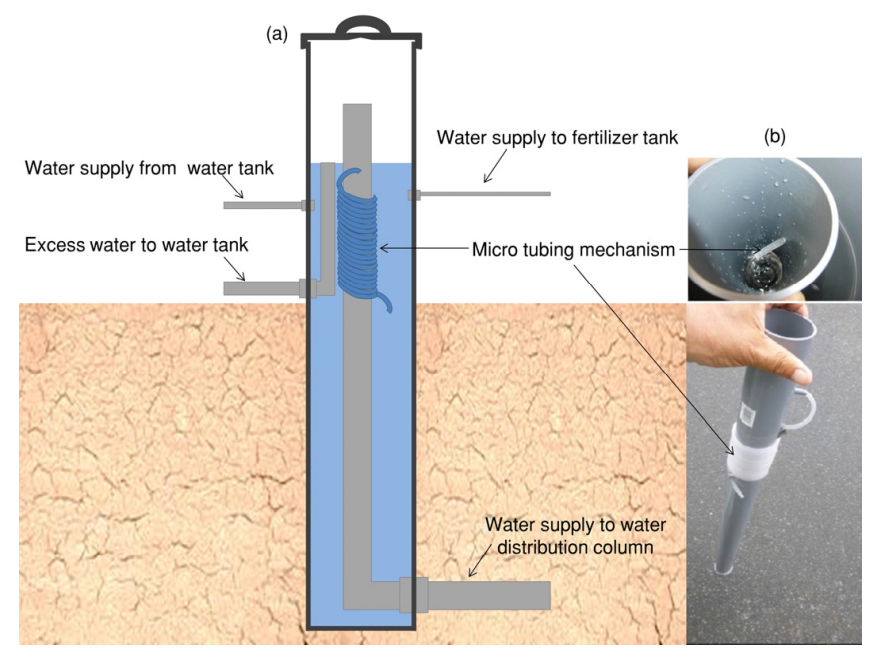

Figure 3. Water supply column (a) Schematic diagram of water supply column (b) Use of micro tubing mechanism.

\subsubsection{Fertilizer Tank}

Fertilizer dissolved in water is added to a compressible bag inside the fertilizer tank. The water fed by the water column creates pressure inside the fertilizer tank, which compresses the bag and thus releases the fertilizer at very low rates into the irrigation system (Figure 4). 


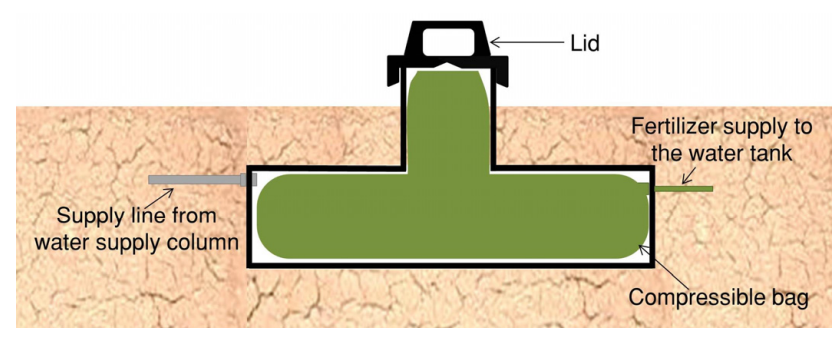

Figure 4. Schematic diagram of fertilizer tank.

\subsection{Water Distribution System}

The water distribution system is the part responsible for distributing the irrigation water equally over the field. It includes a water distribution column at the head end of the field that distributes the water equally among the OPSIS lines, polyvinyl chloride (PVC) or metal sheet to control percolation, and perforated pipes buried horizontally under the field surface to irrigate the field.

\subsubsection{Water Distribution Column}

The water distribution column (Figure 5) distributes water to 5-7 perforated pipes (OPSIS lines) buried below the soil surface. The mechanism in the water distribution column allows water to be distributed equally to all OPSIS lines despite any irregularities in the land. Equal distribution of water to all OPSIS lines is ensured by having the same height of water in the discharge tubes. When several water distribution columns are used on slopes, the equal distribution of water can be ensured by adjusting the discharge tubes in all water distribution columns to be at the same level (Figure 6).



Figure 5. Schematic diagram of water distribution column of OPSIS.

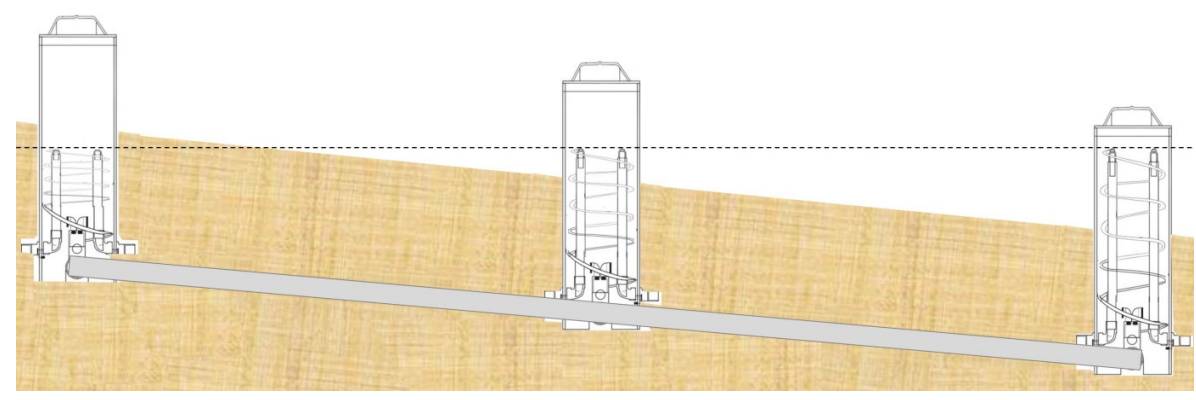

Figure 6. OPSIS can ensure equal discharge on sloping land. 


\subsubsection{Perforated OPSIS Lines}

Perforated 50-mm pipes release the water. When OPSIS is operating, water flows under gravity along the pipes. As the water advances, it can move to the outside soil, depending on the water potential. As water moves outside, the soil becomes saturated. Thereafter, the water potential of the outside soil and inside of the pipe reaches equilibrium. This equilibrium controls the amount and rate of irrigation. Further, the water starts to move upward from the saturated layer owing to the water potential created by matrix effects such as capillary action created via surface tension. As water moves upward, the moisture content of root zone soil increases and provides irrigation water to the crop. For crops planted in rows, the spacing of the OPSIS lines could be maintained to match the row spacing. In sandy soils, closer OPSIS lines would be preferred, whereas in clayey soils, a much wider spacing may be used. However, field and laboratory experiments on water distribution confirmed that it is advisable to maintain a distance of about 1-3 m between two OPSIS lines according to the soil type and crop spacing to ensure an even water supply for all crops while minimizing costs and water losses. Field and laboratory experiments on water distribution, workability condition and possible damage by tillage equipment confirmed that the depth of the lines could vary between 30 and $60 \mathrm{~cm}$ according to the soil type and the root zone depth.

A waterproof PVC or metal sheet can be used to control percolation losses. The sheet is buried in an inverted trapezoidal shape (Figure 7). Ability to control percolation losses, effect on crop yield and the availability of materials were considered when determining the size and shape of the PVC or metal sheet to control percolation losses. After a series of field and laboratory experiments, optimum minimum height to minimize percolation was identified as $15 \mathrm{~cm}$. Therefore, the optimum size of the shape has been determined to be $12 \mathrm{~cm}$ wide at the base, $30 \mathrm{~cm}$ wide at the top, and $15 \mathrm{~cm}$ high considering the prices of materials available in the market. The perforated pipe is positioned in the center of the shape.

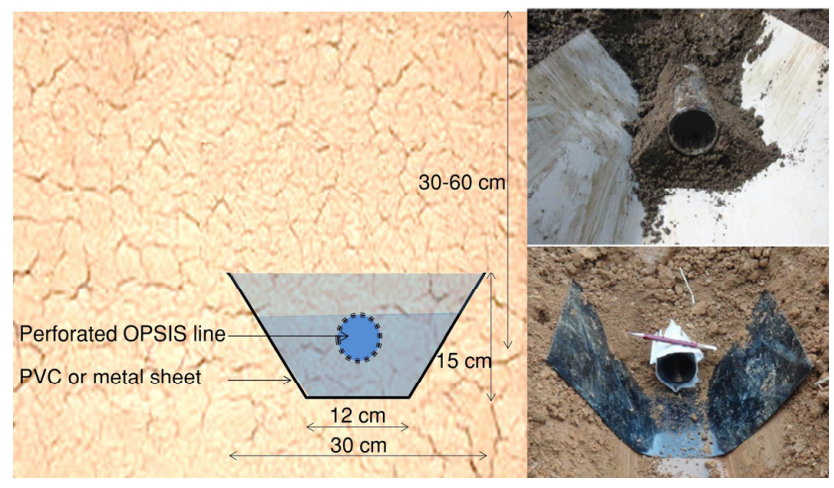

Figure 7. Use of polyvinyl chloride or metal sheet to control percolation losses.

\subsection{OPSIS can Act as a Drainage System}

During the rainy season (when OPSIS might not operate, owing to low solar radiation) the water in the saturated soil can enter the perforated pipes following the water potential gradient. As water is circulating, the tail-end water collects in the drainage pipe and is diverted to the water tank. Thus, OPSIS could act as a subsurface drainage system during rainy periods.

Figure 8 shows the daily rainfall, irrigation or drainage by OPSIS, and level of soil saturation (percent of water-filled volume to the total porosity of the soil) in the root zone area of the experiment field in Itoman, Okinawa, Japan during July 2014. The irrigation or drainage axis shows the net amount of water that goes out of (positive values) or comes into (negative values) the water tank. Positive values represent the irrigation while negative values show the amount of drainage. The level of soil saturation (\%) in the root zone area every day was calculated using daily soil moisture (volume basis) and soil porosity. It shows that OPSIS can manage soil moisture content at desirable levels even 
in very high rainfall seasons, such as that shown in Figure 8, where rainfall was $832 \mathrm{~mm}$ per month, including a maximum daily rainfall of $350 \mathrm{~mm}$.

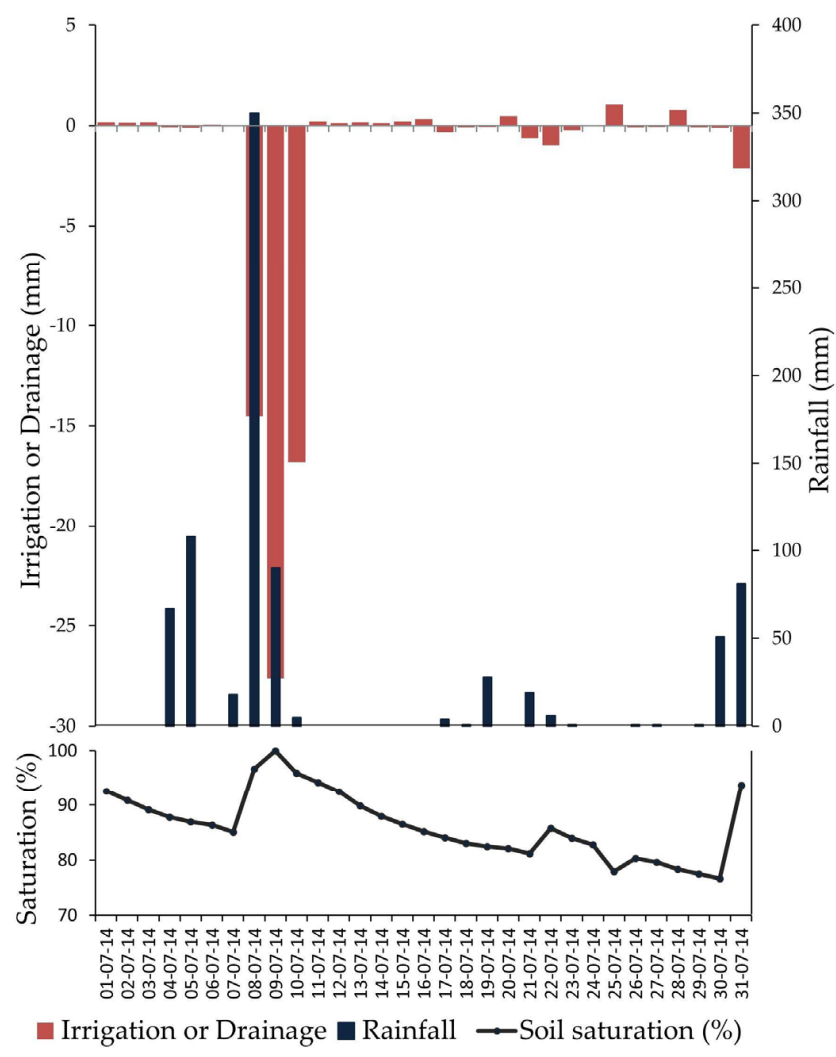

Figure 8. Variation in rainfall, irrigation/drainage, and percentage of soil moisture saturation.

\subsection{System Installation}

The major component of OPSIS installation is the laying out of the perforated OPSIS lines. Initially this was done by digging with a conventional excavator with a bucket. Since this is time consuming and expensive, an attachment was developed to lay out the system more efficiently and effectively. The attachment is able to lay out both the pipe and the sheet simultaneously, thus drastically cutting down the cost and time of installation while significantly improving the workability and accuracy of the system layout. The attachment is being developed to further reduce the initial establishment cost and accuracy of the system layout (Figure 9).

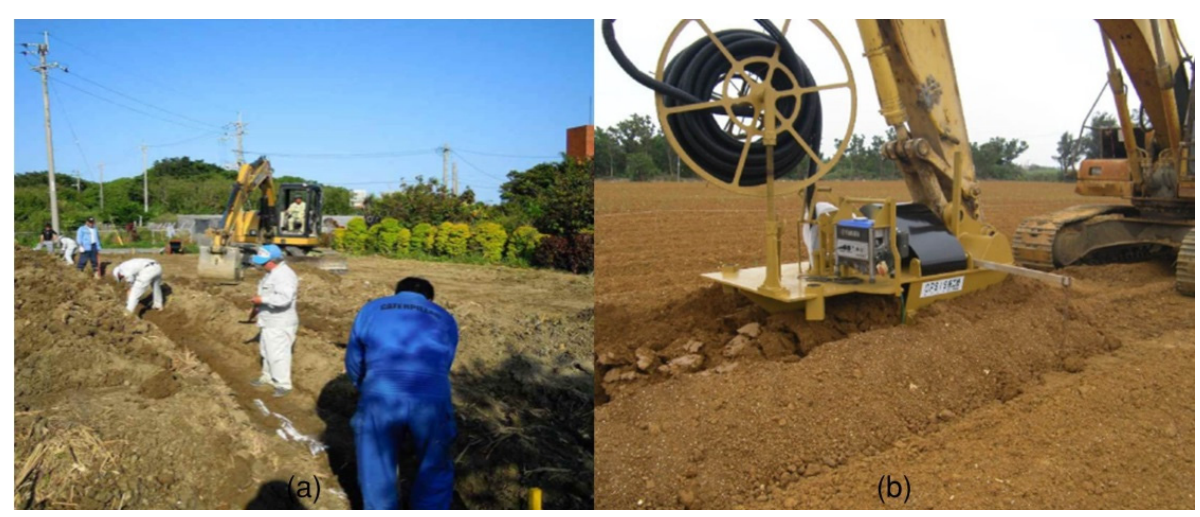

Figure 9. Installation of OPSIS lines (a) Manually laying out lines, (b) Use of machine to lay out lines. 


\subsection{Field Testing of OPSIS}

Field experiments were set to examine the optimum depth of installation, optimum number of OPSIS lines per water distribution column, possible length of OPSIS lines. Further, the growth and yield performances of sugarcane, maize and soybean with OPSIS were tested in different parts of Japan. Some key results showed that maize and soybean with OPSIS reported $40 \%$ and $50 \%$ higher yields, respectively, compared to surface irrigation methods. Field experiments conducted during 2012-2014 to study the performance of OPSIS showed that OPSIS increased the fresh cane yield by $79-116 \%$ compared to the rainfed conditions, as attributed by higher plant height, cane diameter and a higher number of millable stalks per unit area. Figures 10 and 11 shows the growth and yield performances of sugarcane with OPSIS compared to rainfed conditions.

a

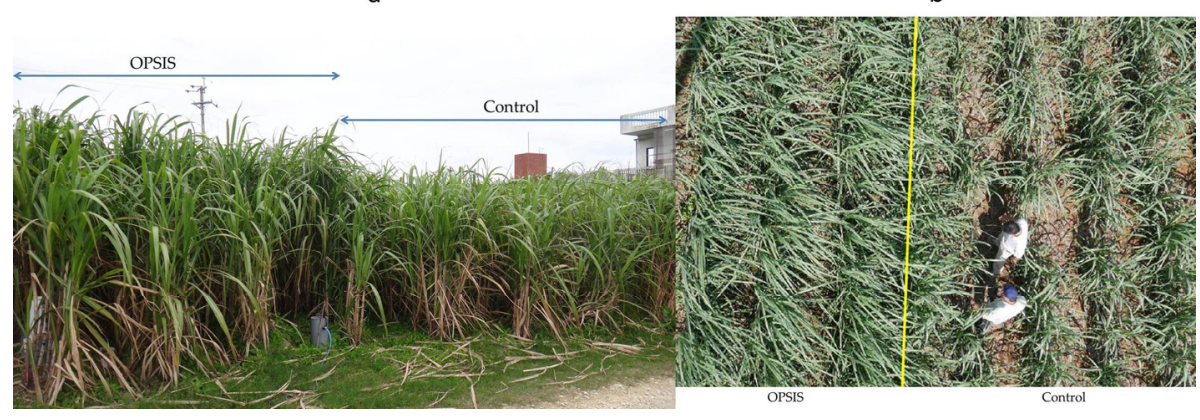

Figure 10. Growth of sugarcane with OPSIS and rainfed conditions (a) Plant height, (b) Canopy cover.

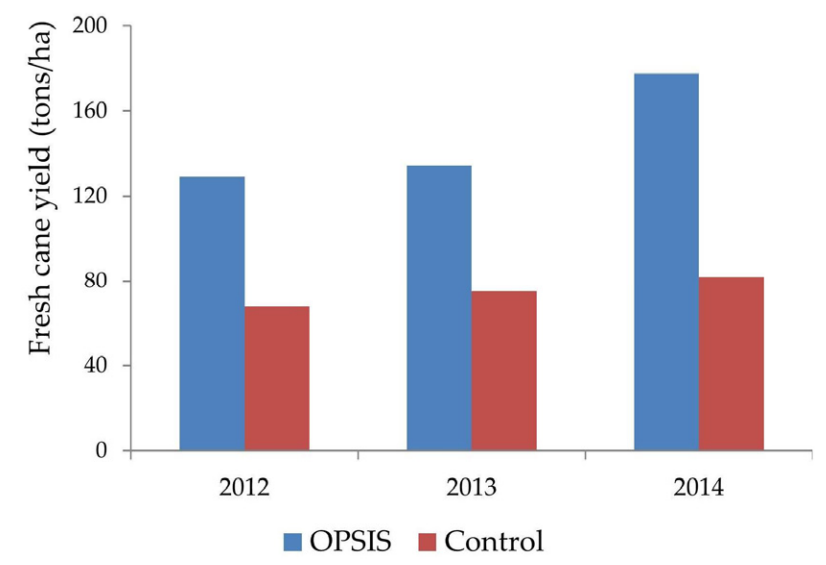

Figure 11. Fresh cane yield of sugarcane with OPSIS and rainfed condition.

\section{Discussion}

\subsection{Special Features of OPSIS}

A series of field and laboratory experiments were carried out to examine the performances of OPSIS. Based on the results, observations and experiences, the following special features of OPSIS were identified.

\subsubsection{Water-Saving Irrigation Method}

OPSIS shows improved water-saving capabilities compared with other irrigation methods as it is able to function with minimum percolation, evaporation, and surface runoff. 


\subsubsection{Ensures Uniform Water Distribution}

OPSIS can be used on slopes, where surface irrigation is not suitable. It requires less attention to land leveling than surface irrigation methods, and it is better than other irrigation methods in achieving the equal distribution of irrigation water on slopes.

\subsubsection{Ensures Good Crop Yields}

Field experiments conducted in different places in Japan using sugarcane, maize, and soy beans as test crops confirmed the high yields obtained with OPSIS compared with other irrigation methods.

\subsubsection{Ensures Sanitary Field Conditions}

Since the surface layer remains dry, OPSIS provides optimum workability conditions and allows the maintenance of sanitation in the field. The dry state of the topsoil helps to maintain good workability and creates low humidity, especially in protected greenhouses. No topsoil splattering or erosion hazards occur, as there are no surface water droplets or flowing water with OPSIS.

\subsubsection{Enables Fertigation}

Water-soluble fertilizers can be effectively used with the irrigation water with OPSIS. The slow-release nature ensures higher fertilizer use efficiency than can be achieved under other fertigation or fertilizer application methods.

\subsubsection{Minimal Operational Costs}

OPSIS is powered by solar energy, and therefore it has no real energy costs. As an automatic system, it also requires minimum human supervision for irrigation during the cropping season. As a subsurface system, it causes minimal disturbance to other field operations. Further, it does not require comprehensive land leveling. Therefore, OPSIS has the lowest operational costs of all irrigation methods.

\subsubsection{No Clogging}

No large debris can enter to water distribution system as water has to pass the micro tube in the water supply column. As an open-ended system, OPSIS do not experience negative pressures inside the lines nor soil ingestion when stopping the system, which usually happens in subsurface drip irrigation systems.

\subsubsection{Long Durability}

Once OPSIS is installed, it can be used for years without any need for re-installation because there is no damage by sunlight, animals or farm machinery.

\subsubsection{Drainage System}

OPSIS can act as a subsurface drainage system. Therefore, no separate drainage system is required for water management in fields where OPSIS is installed.

\subsubsection{Environmentally-Friendly Technology}

Being a solar-powered irrigation system, OPSIS does not consume any fossil fuels. As a subsurface fertigation system, it emits less greenhouse gases than the surface application of fertilizers or fertigation. Further, owing to minimum percolation losses and the slow release of fertilizer, OPSIS helps to minimize the contamination of groundwater with fertilizer. 


\subsection{Limitations of OPSIS}

The installation of OPSIS requires considerable initial cost. However, factors such as no need for a separate drainage system, high crop yields, minimum operational costs, and long durability can help recover the high initial cost of installation within few years. As some percolation losses are inevitable, losses of fertilizer can happen with OPSIS. After the installation of the system, deep plowing will be impossible as it can damage the system. Therefore, to the extent possible, care should be taken to avoid the development of a hardpan, and suitable machinery that can break up the hardpan should be used only with utmost care.

\section{Recommendations}

Although OPSIS is commercially available for sugarcane farmers in Okinawa, Japan, it needs validation of its performance and further improvement to make it a more highly efficient and low-cost irrigation method. Further, to help farmers operate OPSIS with minimal problems and to make irrigation more profitable and sustainable, guidelines for best management practices need to be developed and introduced.

Installation of OPSIS requires a considerable initial investment; therefore, new strategies and technologies should be developed to minimize the initial cost.

OPSIS provides irrigation water to the field automatically whenever there is solar radiation available to operate the pump. This can lead to some percolation losses, especially during dry periods and in fields with low groundwater levels or sandy soil. Changing the automatic operational mechanism to one that adjusts the pump according to soil moisture by incorporating soil moisture sensors could be helpful to further reduce percolation losses and maximize the lifespan of the pump.

The optimum depth at which to install the perforated OPSIS pipes may vary depending on the soil type, crop to be grown, and depth to the groundwater table. Since OPSIS has been tested with only a limited number of crops and soil types, further studies should be carried out under different soil and climate conditions with different crops.

Patterns of root distribution that develop with subsurface irrigation systems might differ from those that develop with other irrigation systems. Therefore, studies focused on root distribution and soil moisture extraction patterns might be helpful for the further development of OPSIS.

It might be difficult to break the hardpan after installing the OPSIS. Therefore, new technologies or strategies might have to be developed to minimize the creation of hardpans and to break them without damaging OPSIS lines.

OPSIS has been tested only for small- and medium-scale fields in Japan. The maximum length of OPSIS lines tested was less than $100 \mathrm{~m}$. Therefore, its applicability for large-scale fields has yet to be examined.

Author Contributions: T.O. and K.W. designed the OPSIS; M.H.J.P.G., K.S., T.N., M.K., T.O., H.K., H.U. and K.W. conceived, designed and performed the experiments; M.H.J.P.G., K.S., T.O., T.N. and M.K. analyzed and interpreted the data; M.H.J.P.G. and K.S. wrote the paper; all authors read and approved the final manuscript.

Conflicts of Interest: The authors declare no conflict of interest.

\section{References}

1. FAO. Status and trends in land and water resources. In The State of the World's Land and Water Resources for Food and Agriculture (SOLAW): Managing Systems at Risk; Routledge: London, UK, 2011; Chapter 1; pp. $19-62$.

2. IPCC. Food security and food production systems. In Climate Change 2014: Impacts, Adaptation, and Vulnerability. Working Group II Contribution to the Fifth Assessment Report of the Intergovernmental Panel on Climate Change; Technical Report for Cambridge University Press: Cambridge, UK; New York, NY, USA, 2014; Chapter 7; pp. 485-534.

3. Webber, H.; Gaiser, T.; Ewert, F. What role can crop models play in supporting climate change adaptation decisions to enhance food security in Sub-Saharan Africa? Agric. Syst. 2014, 127, 161-177. [CrossRef] 
4. Roudier, P.; Sultan, B.; Quirion, P.; Berg, A. The impact of future climate change on West African crop yields: What does the recent literature say? Glob. Environ. Chang. 2011, 21, 1073-1083. [CrossRef]

5. Sharma, B.; Molden, D.; Cook, S. Water use efficiency in agriculture: Measurement, current situation and trends. In Managing Water and Fertilizer for Sustainable Agricultural Intensification, 1st ed.; Drechsel, P., Heffer, P., Magen, H., Mikkelsen, R., Wichelns, D., Eds.; International Fertilizer Industry Association (IFA), International Water Management Institute (IWMI), International Plant Nutrition Institute (IPNI) and International Potash Institute (IPI): Paris, France, 2015; Chapter 3; pp. 39-64.

6. Ali, M.H. Water application methods. In Practices of Irrigation and On-farm Water Management; Springer Science: Berlin, Germany, 2011; Volume 2. [CrossRef]

7. Van Lier, H.N.; Pereira, L.S.; Steiner, F.R. CIGR Handbook of Agricultural Engineering. Am. Soc. Agric. Eng. 1999, 1, 297-369.

8. Strelkoff, T.S.; Clemmens, A.J. Hydraulics of surface systems. In Design and Operation of Farm Irrigation Systems; Hoffman, G.J., Evans, R.G., Jensen, M.E., Martin, D.L., Elliott, R.L., Eds.; American Society of Agricultural and Biological Engineers: St. Joseph, MI, USA, 2007; Chapter 13; pp. 436-498.

9. Martin, D.L.; Heermann, D.F.; Madison, M. Hydraulics of sprinkler and microirrigation systems. In Design and Operation of Farm Irrigation Systems; Hoffman, G.J., Evans, R.G., Jensen, M.E., Martin, D.L., Elliott, R.L., Eds.; American Society of Agricultural and Biological Engineers: St. Joseph, MI, USA, 2007; Chapter 15; pp. 532-556.

10. Mikkelsen, R.; Hartz, T.K.; Rusan, M.J.M. Challenges of increasing water and nutrient efficiency in irrigated agriculture. In Managing Water and Fertilizer for Sustainable Agricultural Intensification, 1st ed.; Drechsel, P., Heffer, P., Magen, H., Mikkelsen, R., Wichelns, D., Eds.; International Fertilizer Industry Association (IFA), International Water Management Institute (IWMI), International Plant Nutrition Institute (IPNI) and International Potash Institute (IPI): Paris, France, 2015; Chapter 8; pp. 168-186.

11. Evans, R.G.; Wu, I.; Smajstrala, A.G. Microirrigation Systems. In Design and Operation of Farm Irrigation Systems; Hoffman, G.J., Evans, R.G., Jensen, M.E., Martin, D.L., Elliott, R.L., Eds.; American Society of Agricultural and Biological Engineers: St. Joseph, MI, USA, 2007; Chapter 17; pp. 632-679.

12. Payero, J.O.; Yonts, C.D.; Irmak, S. Advantages and Disadvantages of Subsurface Drip Irrigation; Nebraska Extension, Institute of Agriculture and Extension, University of Nebraska-Lincoln: Lincoln, NE, USA, 2005.

13. Lamm, F.R.; Camp, C.R. Subsurface drip irrigation. In Micro Irrigation for Crop Production—Design, Operation and Management; Lamm, F.R., Ayars, J.E., Nakayama, F.S., Eds.; Elsevier: Amsterdam, The Netherlands, 2007; Chapter 13; pp. 473-551.

14. Li, J.; Chen, L.; Li, Y.; Liu, Y. Field Evaluation of Emitter Clogging in Subsurface Drip Irrigation Systems. In Proceedings of the ASABE Annual International Meeting, Providence, RI, USA, 29 June-2 July 2008. [CrossRef]

(C) 2017 by the authors. Licensee MDPI, Basel, Switzerland. This article is an open access article distributed under the terms and conditions of the Creative Commons Attribution (CC BY) license (http://creativecommons.org/licenses/by/4.0/). 